\title{
Working
}

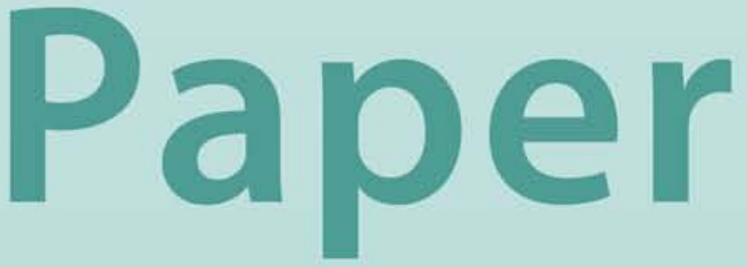




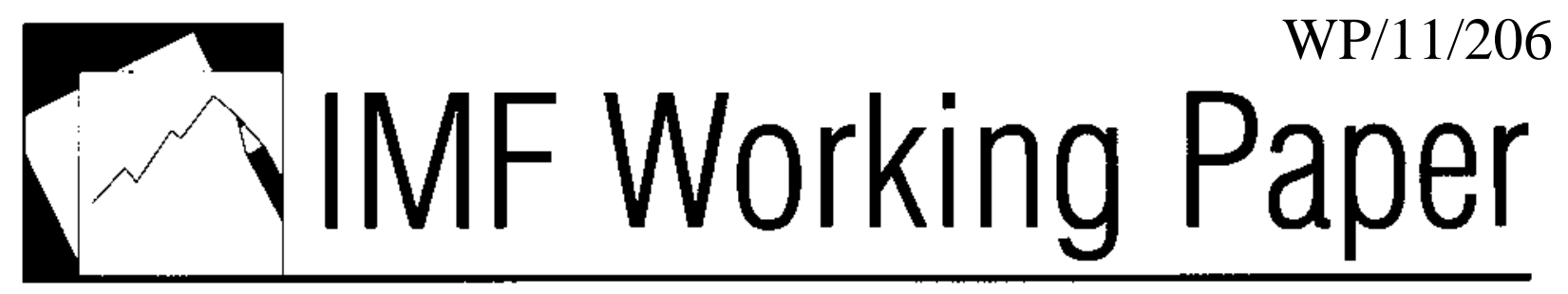

The Taxation and Regulation of Banks

\author{
Michael Keen
}




\title{
IMF Working Paper
}

Fiscal Affairs Department

\section{The Taxation and Regulation of Banks}

\section{Prepared by Michael Keen ${ }^{1}$}

August 2011

\begin{abstract}
This Working Paper should not be reported as representing the views of the IMF. The views expressed in this Working Paper are those of the author(s) and do not necessarily represent those of the IMF or IMF policy. Working Papers describe research in progress by the author(s) and are published to elicit comments and to further debate.

The financial crisis has prompted a reconsideration of the taxation of financial institutions, with practice outstripping principle: France, Germany, the United Kingdom and several other European countries have now introduced some form of bank tax, and the U.S. administration has revived its own proposal for such a charge. This paper considers the structure, appropriate rate, and revenue yield of corrective taxation of financial institutions addressed to two externalities, consequent on excessive risk-taking, prominent in the crisis: those that arise when such institutions are simply allowed to collapse, and those that arise when, to avoid the harm this would cause, their creditors are bailed out. It also asks whether corrective taxation or a regulatory capital requirement is the better way to address these concerns. The results suggest a potential role for taxing bank borrowing, perhaps as an adjunct to minimum capital requirements, at marginal rates that rise quite sharply at low capital ratios (but are likely lower when the government cannot commit to its bailout policy), reaching levels higher than those of the bank taxes so far adopted or proposed.
\end{abstract}

JEL Classification Numbers: H21, H23, G21

Keywords: Bank taxation; corrective taxation; bank failure

Author’s E-Mail Address: MKeen@imf.org

\footnotetext{
${ }^{1}$ Acknowledgements: For their helpful comments and suggestions, I am grateful to Alan Auerbach, Stijn Claessens, Carlo Cottarelli, Giovanni Dell’Ariccia, Ruud de Mooij, Michael Devereux, Gregorio Impavido, Luc Laeven, Jack Mintz, Michael Moore, Ceyla Pazarbasioglu, Lev Ratnovksi, Dan Shaviro, Joel Slemrod, and Beatrice Weder di Mauro. Views and errors, however, are mine alone, and should not be attributed to the International Monetary Fund.
} 
I. Introduction

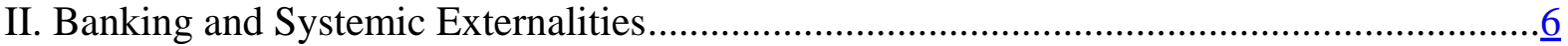

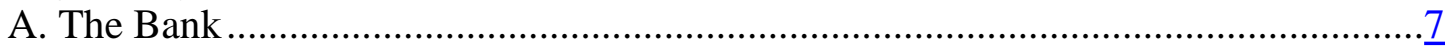

B. Financial Sector Externalities.................................................................... 10

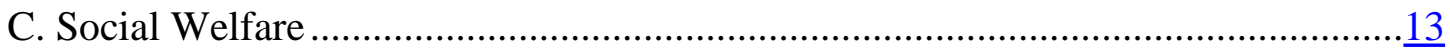

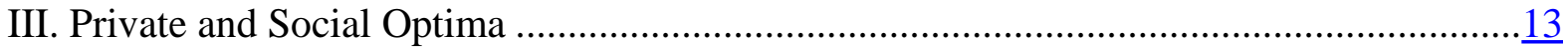

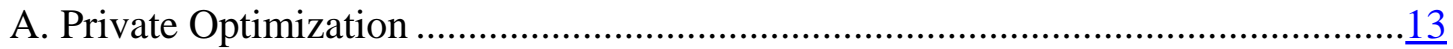

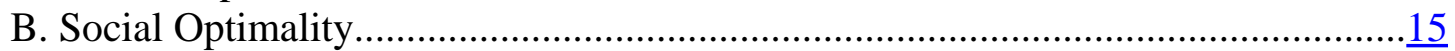

C. Inefficiency and Corrective Taxation.......................................................... $\frac{16}{17}$

D. Calibrating the Optimal Tax on Borrowing ................................................... $\frac{17}{19}$

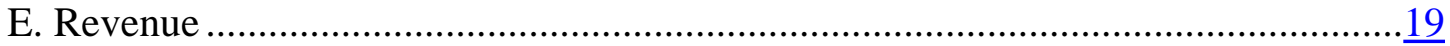

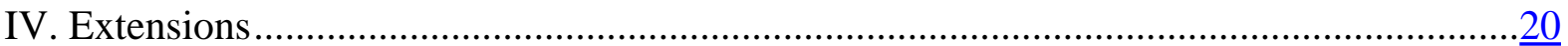

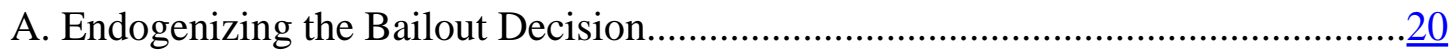

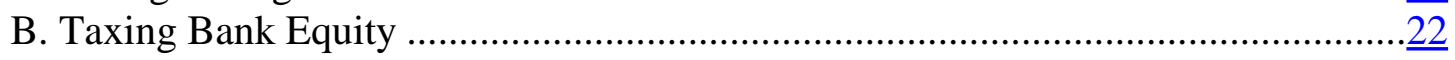

V. Comparing Tax and Regulation .........................................................................

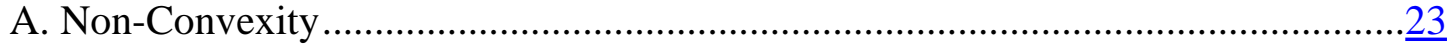

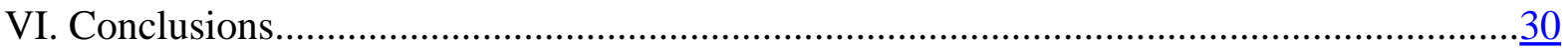

Table

1. Optimal Corrective Tax on Borrowing to Address Collapse Externality ..........................18

Figures

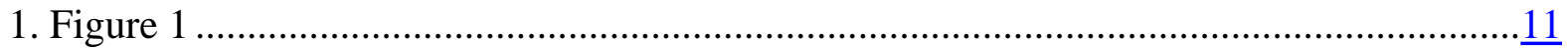

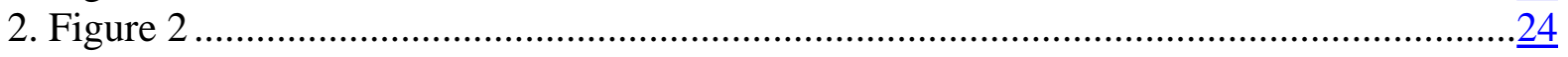

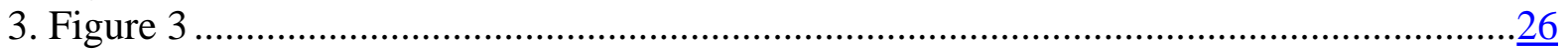

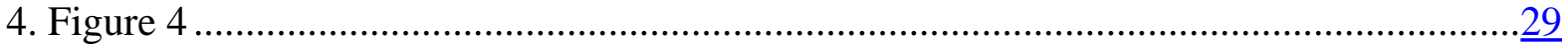

Appendices

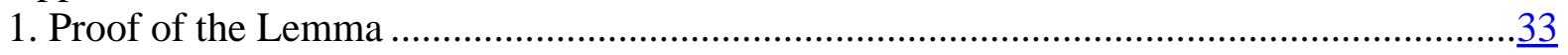

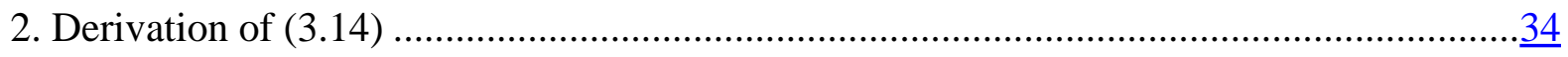

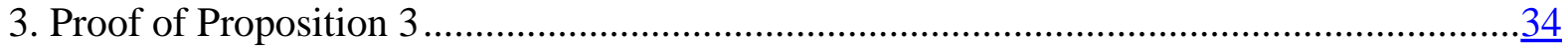

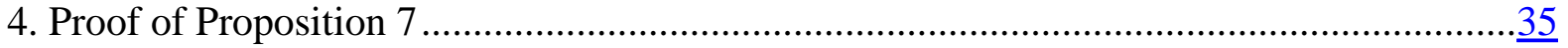

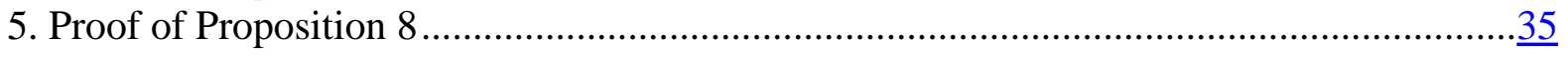

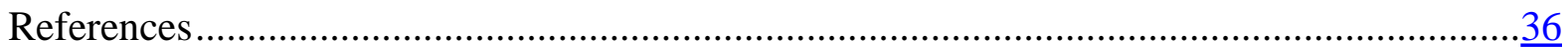




\section{INTRODUCTION}

One consequence of the financial crisis, which erupted in 2008, has been a fundamental reconsideration of the tax treatment of the financial sector. In part, this has meant recognizing that pre-existing tax distortions may be more costly than had been supposed. ${ }^{2}$ The more fundamental issue raised, however, is whether new types of tax instruments applied to the financial sector might have a purposive role in limiting the likelihood and social damage from financial failures. Responding to a request from the G-20, a charge of this type was proposed in IMF (2010a), but action has been far ahead of analysis. The United Kingdom, for instance, introduced in January 2011 a Bank Levy, levied ${ }^{3}$ at 7.5 basis points on (essentially) banks’ uninsured debt obligations, “...to encourage banks to move away from risky funding models that threaten the stability of the financial sector and wider economy" (HMRC, 2010). France, Germany, Sweden, and others-a total of ten EU members-have introduced some special charge on financial institutions. And in the United States, proposals for such a charge have recently been revived in the President's 2011 budget proposal. Regulation, of course, has traditionally been the dominant approach to dealing with the externalities associated with the failure of financial institutions. But the evident failings of existing regulatory and microprudential measures surely suggests a potential role for other instruments. The aim of this paper, with the still-open reform agenda in mind, is to explore the potential design of tax instruments to address the challenges posed by (even the possibility of) financial sector failures, and to consider their merits relative to conventional regulatory tools.

The challenges for policy design are considerable. The crisis was a powerful, painful reminder of the strongly adverse external effects that the collapse, and potential collapse, of systemic financial institutions can have. ${ }^{4}$ In their detail, the mechanics of these effects, operating both across financial institutions and between the financial and nonfinancial sectors, are complex and varied. ${ }^{5}$ Their ultimate consequences, however, have been clear. Many governments, lacking tools to resolve systemically important institutions in an orderly

\footnotetext{
${ }^{2}$ Prominent among these are the exemption of most financial services under the VAT and the tax bias toward debt finance created by the deductibility of interest but not the cost of equity finance at corporate level: see IMF (2011a). Also not considered here is the taxation of bonuses, another area of (usually explicitly temporary) innovation: see Radulescu (2010).

${ }^{3}$ From May 2011.

${ }^{4}$ There is evidence too of positive externalities from well-functioning financial systems (Levine, 2005), but these are not at issue here.

${ }^{5}$ The former include, for instance, the effects of firesale externalities as distressed asset sales by one institution lead to price reductions that jeopardize the solvency of others: this is a pecuniary externality that has real effects as a consequence of incompleteness of markets and regulatory and other constraints. The latter include the likelihood that shaper credit constraints will limit opportunities open to nonfinancial businesses. Bank of England (2009) and Wagner (2010) review the main forms of externalities at work.
} 
fashion, faced the dilemma of either letting such collapse occur, allowing these externalities full play and accepting the economic disruption that would imply or, instead, committing sufficient public funds for bailouts to avert this damage, but in so doing trigger another kind of externality, and potential inequities, by creating an expectation of future bailouts. Or, as in practice, doing some of both.

The social costs associated with either course of action have proved very high. Reviewing the literature, Basel Committee on Banking Supervision (BCBS; 2010) find a median cumulative output loss from banking crises of 63 percent of initial GDP, and a mean of over 100 percent. For the recent crisis, IMF (2010a) put the cumulative loss at already 25 percent of GDP by end-2009, for advanced countries that experienced a systemic crisis. In narrower fiscal terms, while recovery and charging operations-from the sale of assets taken into public ownership, for example - may mean that the final costs of the direct fiscal intervention will be small this time around, governments' exposures at the height of the crisis were huge: through guarantees and the like, the advanced G-20 economies committed to making an average of 25 percent of GDP available for support operations. These fiscal costs are of course a transfer, implying a real resource loss only to the extent of the distortionary cost of raising the public funds; but they arise in circumstances where that cost may be especially high, and, moreover, have raised fairness concerns of which policymakers remain keenly aware. A central lesson of the crisis has thus been that preexisting policies did a poor job of limiting adverse externalities from the distress and failure of systemically important institutions - and the central challenge for reform is to identify and put in place better ones.

There are broadly two main ways in which one can address any externality: by regulating aspects of behavior directly, or by using tax measures to influence that behavior indirectly. ${ }^{6}$ In relation to financial activities, regulation has long been dominant, in the form, in particular, of minimum capital requirements for banks. Taxation-except in the shape of deposit insurance, justified primarily as a defense against bank runs- - has played no significant role. ${ }^{7}$ But it could. An alternative (or supplement) to regulatory capital requirements, for instance, would be to use tax measures—-such as taxing banks' wholesale borrowing - to discourage low capitalization. But, historically, that was not the route chosen. Instead, the regulatory approach has had an unquestioned dominance in relation to financial sector that is in stark contrast to the standard prescription for tax-type measures as the best way to dealing with many other externalities, such as those associated with climate change.

\footnotetext{
${ }^{6}$ Of course it may be-in general, probably is—optimal to deploy elements of both (Christiansen and Smith, 2009), a point that emerges later in the present context.

${ }^{7}$ The regulatory literature sometimes refers to capital regulation as a price-based instrument, since it effectively raises the shadow value of capital. But one of the concerns here is with precisely those circumstances in which capital requirements are not equivalent to a tax instrument.
} 
Two sets of issues consequently arise, and these are the focus of this paper. The first is the characterization of optimal tax policies addressed to easing the policy dilemma above: the proper base, likely level and-relevant to public concerns that the financial sector pay for at least the public support it receives - revenue yield. The second is whether taxation or regulation is the best way to approach these policy challenges: Is the dominance of the regulatory approach to dealing with financial sector externalities warranted, or is there a more purposive role in this area for corrective taxation?

It may seem that the answer to this second question, whatever its theoretical interest, can have little practical importance, there being no realistic prospect of displacing the current dominance of the regulatory approach and associated institutional framework. But bank $\operatorname{taxes}^{8}$ are, as a matter of fact, being introduced. More fundamentally, the established dominance of the regulatory approach is in relation to microprudential policies - at the level of the individual institution - whereas the focus of the current policy debate is on the need to establish effective macroprudential frameworks - focused on the stability of the overall financial system. In this context, policymakers have more of a clean sheet: the September 2010 'Basel III' agreement, in particular, focuses on tighter and redefined capital requirements for individual institutions and leaves strategies for dealing with macroprudential risks and the challenges posed by systemically important institutions unarticulated. This makes it critical to understand, in particular, the comparative merits of, on the one hand, imposing additional capital requirements on systemically important institutions [as analyzed, for instance, in Bank of England (2009), Gauthier, Lehar, and Souissi (2010), and IMF (2010b)], or, on the other, discouraging them from choosing inappropriately low capital ratios by imposing some tax on their unsecured borrowing (of the kind recently introduced in Germany, the United Kingdom, and elsewhere in Europe).

The aim here is to make progress on these two issues. It first explores the design of tax instruments (to discourage inappropriately low capital ratios) in addressing the externalities associated with the actual and potential failure of financial institutions-including their possible magnitude and revenue yield relative to the cost of the underlying social damageand then asks whether or not they are a better means to this end than are regulatory policies (acting directly on capital ratios). In the first aspect, the paper is related to others that have argued for corrective taxes related to unsecured/short-term borrowing, whether-as herebecause of the links with the likelihood of failure or for other reasons. ${ }^{9}$ The second aspect-

\footnotetext{
${ }^{8}$ For brevity we speak of 'banks' and 'bank taxes' throughout, though in both principle and practice the issues extend beyond narrowly-defined banks.

${ }^{9}$ Closest in spirit to this aspect of the analysis here is Acharya et al. (2010). Less formal arguments to the same effect are in Shin (2010) and in the proposal of Perotti and Suarez (2009) for a corrective tax on maturity mismatches that would be, in effect, largely a tax on short-term debt. Several papers have argued for corrective taxes on unsecured borrowing on other grounds. In Huang and Ratnovski (2009) for instance, it serves to reduce banks' funding reliance on creditors with such high seniority that they may impose inefficient liquidation in response to noisy signals on the institution's prospects; in Jeanne and Korinek (2010) it serves to discourage
} 
the question of instrument choice-has received almost no attention. While a number of recent papers argue for some kind of corrective tax on financial activities, the characterization of optimal policy in these terms is essentially an analytical convenience, with corresponding regulation seen as just as good a way to implement it. ${ }^{10}$ There are, of course, many aspects to the comparison of tax and regulatory approaches, both conceptual and practical. Taxation, for instance, means smaller private 'buffers' to deal with unexpected stresses (resources being taken out of the bank) but higher buffers in the public sector; the relative desirability of which will depend on correlation between the shocks to institutions' financial positions. And international coordination has been easier to achieve on the regulatory side (as with the widespread adoption of Basel standards) than in relation to taxation. This paper does not attempt a full comparison between tax and regulatory approaches, ${ }^{11}$ but focuses on key incentive-related issues.

The plan of the paper is as follows. Section II sets out a model of a representative bank whose decisions determine its own risk of failure, and explores the two implied externalities: one if such failure is allowed to have its full social consequences, the other if the government is perceived as committed to prevent those costs arising by, if necessary, bailing out creditors. Section III characterizes the optimal corrective tax, explores its likely magnitude, and considers whether the associated revenue would cover the expected social costs of outright failure and of bailout. Section IV extends the analysis, notably to endogenize the government's bailout decision. Section $V$ then compares the optimal corrective tax with the alternative of imposing capital requirements, in terms of implementability, effectiveness in dealing with uncertainty and asymmetry of information between policymakers and the bank. Section VI concludes.

\section{BANKING AND SYSTEMIC EXTERNALITIES}

This section develops a simple model of a representative bank, with endogenous failure risk, that allows a characterization and exploration of the policy dilemma raised the outset: the choice between allowing a failed institution to collapse or, to avoid the damage this would cause, bailing it out.

borrowing that increases asset prices and so, in the presence of collateral constraints, amplifies volatility by allowing others to borrow more too; see also Bianchi and Mendoza (2010) and Korinek (2009). None of these papers, however, explicitly compares corrective taxation with regulatory measures to the same end.

${ }^{10}$ As is noted, for instance, by Korinek (2009).

${ }^{11}$ IMF (2010a) provide a broad review of the comparison between taxation and regulation in the financial sector; Keen (2011) elaborates on some of these, and provides an informal account of some of the arguments below. Shackelford, Shaviro, and Slemrod (2010) discuss aspects of financial sector taxation in light of the crisis. 


\section{A. The Bank}

The 'bank' has equity capital in an amount $K$, taken (until Section IV) as given, and chooses how much to borrow, $D$ ('debt', 'deposits'), and lend, $L$ ('loans'), with

$$
L=K+D
$$

It offers creditors a rate of return of $\rho$ (inclusive of return of principal), the determination of which is considered below. The return on loans (also inclusive of principal) $r \geq 0$ is stochastic; its distribution, described by density $\phi$ and (twice continuously differentiable) distribution function $\Phi$, is taken as given, with

$$
\phi(r)>0 \text { for } r>0 ; \phi(0)=0
$$

and, denoting the risk-free return by $\zeta$

$$
\int_{-\infty}^{\infty}(r-\zeta) \phi(r) d r>0 .
$$

Loans are thus expected to yield more than the safe return: this ensures that they are socially desirable ${ }^{12}$ and that banks are willing to borrow in order to make them.

The assumed exogeneity of the distribution of returns means that the bank has no choice as to the riskiness of its assets. This does not mean, however, that it has no risk-taking decision to make. To the contrary, this simplifying assumption serves to focus attention on the most fundamental of any bank's risk decisions: that of how large a risk to accept that the return on its assets will prove so low, relative to its capital base and promises to creditors, that the bank fails and equity is wiped out.

Such failure arises if and only if the bank is unable to meet its obligations to creditors in full, which happens if

$$
r L<\rho D
$$

Defining the capital ratio $k \equiv K / L$ [and using (2.1)] this defines a critical return on loans of

$$
R \equiv \rho(1-k)
$$

\footnotetext{
${ }^{12}$ As can be seen from (2.8) below.
} 
below which failure occurs. All else equal, failure is thus less likely the lower is the interest rate at which the bank borrows and the higher is its capital ratio (or the lower is leverage $D / L=1-k)$. Recalling (2.2), the probability of failure is zero if and only if $k=1$.

In the event of bankruptcy, bank owners are assumed to incur costs-beyond the loss of their equity —of $\delta K$. These might be literal bankruptcy costs, a loss of ego rents (as in Dewatripont and Tirole, 1993) or loss of franchise value of the bank (Hellman, Murdock, and Stiglitz, 2000).

Bank owners (and, later, creditors and the government) are risk-neutral. Taking account of limited liability, and ignoring taxes for the moment, their problem is thus to choose $k$ to maximize

$$
P \equiv-\Phi(R) \delta K+\int_{R}^{\infty}\{r L-\rho D\} \phi(r) d r
$$

where $\Phi(R)$ is the probability of failure.

One approach to the determination of $\rho$, the rate at which the bank borrows, is to assume creditors to be myopic, in the sense of taking no account of the possibility that the bank may be unable to repay them: this is the archetypal view of small depositors and provides one rationale for deposit insurance. More at issue in the crisis, however, was the behavior of large and uninsured wholesale depositors, most naturally assumed to be sufficiently sophisticated (and well-informed) to take the possibility of failure into account in their lending decisions. In doing so, we suppose that creditors are also aware of some possibility that the government will protect them in the event of failure: this is modeled by supposing that they perceive some probability $\mu$ (exogenous to their own decisions, but later treated as a choice variable for the government) that they will be fully bailed out, in the sense that in the event of bankruptcy the government will ensure that they receive the return $\rho$ offered by the bank. This 'all or nothing' characterization of the possibility of bailout is of course extreme; creditors might suppose, for example, that government, if it steps in, will not make them fully whole but rather impose some haircut in the form of a return lower than that contracted by the bank (though nevertheless higher than the residual value of the assets). But it is not entirely implausible: holders of credit default swaps issued by AIG, to give just one example, took no haircut. In any case, the characterization through $\mu$ provides a convenient way of characterizing the expected extent of bailout.

Given the alternative of investing at the risk-free rate $\zeta$, and assuming a competitive loan market, creditors will thus require a return $\rho$ such that

$$
\zeta D=\rho D\{1-\Phi(R)\}+\mu \rho \Phi(R) D+(1-\mu) L \int_{-\infty}^{R} r \phi(r) d r
$$


where the first two terms on the right reflect full payment of $\rho$ if either the bank does not fail or it does but creditors are bailed out, and the third ${ }^{13}$ that with failure but no bail out creditors receive only the residual value of assets. Dividing by $K$ and recalling that $R=\rho(1-k)$, (2.7) defines the rate of return on borrowing as a function $\rho(k, \mu)$, routine comparative statics showing that ${ }^{14} \rho_{k}$ and $\rho_{\mu}$ are both strictly negative (except, for the former, when $\mu=1$, in which case the bank can borrow at the safe rate). ${ }^{15}$ This is as expected: the less likely is failure and the higher is the probability of bailout, the lower is the rate at which the creditors will be willing to lend to the bank.

Using (2.7) in (2.6), the bank’s objective function can be written as

$$
P=-\Phi(R) \delta K+\int_{-\infty}^{\infty}\{r L-\zeta D\} \phi(r) d r+\mu K S(k, \mu)
$$

where

$$
K S(k, \mu) \equiv \rho(k, \mu) \Phi[R(k, \mu)] D-L \int_{-\infty}^{R(k, \mu)} r \phi(r) d r
$$

and

$$
R(k, \mu)=\rho(k, \mu)(1-k) .
$$

The expected payoff to bank owners thus comprises three components. The first is the expected private cost of failure. This arises, it should be noted, whether or not the government bails out creditors: equity is assumed to be wiped out whenever the bank fails in the sense of being unable to meet its obligations, any bailout applying only to creditors. The second component is the value that the bank would have in the absence of bailout. Importantly, this is not affected by limited liability: creditors are, by assumption, compensated for any risk to them from this through a higher return. The full implications of limited liability are thus internalized by bank owners, so this is not a source of inefficiency. ${ }^{16}$

\footnotetext{
13 The lower limit of the integral is taken to be $-\infty$ in expressions like this, even though $r$ is assumed nonnegative in all realizations, as a reminder that integration is over a range that includes failure of the bank.

${ }^{14}$ Derivatives are indicated by subscripts for functions several variables, and by a prime for functions of one.

${ }^{15}$ Explicitly:

$$
\begin{aligned}
& \rho_{k}=-\left(\frac{(1-\mu) S}{(1-k)^{2}[1-\Phi(1-\mu)]}\right) \\
& \rho_{\mu}=-\left(\frac{k S}{(1-k)[1-\Phi(1-\mu)]}\right) .
\end{aligned}
$$

${ }^{16}$ As John, John, and Senbet (1993) and Sinn (2003, 2010) stress, limited liability reacquires importance when information is asymmetric between the bank and its creditors. Though the assumption the lenders are fully
} 
The final component-less straightforward, and central in what follows - potentially is. It is the expected value of the bailout, and of interest to owners not because they themselves will be rescued but because it reduces the rate at which they can borrow while the bank is in operation.

\section{B. Financial Sector Externalities}

To capture the dilemma stressed in the introduction, two potential types of externality can arise when the bank fails: those associated with an institution's unmitigated collapse, and those associated with the bailouts by which such collapse can be averted.

\section{The bailout externality}

The second component of the bank's maxim and in (2.8), $\mu K S(k, \mu)$, is the value to the bank-conversely, the revenue cost to the government—of expected public support (topping up the residual value of assets to pay off creditors). This term thus captures the implicit subsidy from the prospect of bailout - the 'too big to fail' subsidy - that is at the heart of much current policy discussion. This bailout subsidy itself is a transfer. Inefficiencies will arise, however, from the incentives of bank owners to exploit it, and from any distortions imposed to finance it; we refer to these as the bailout externality. ${ }^{17}$

The properties of the bailout subsidy $\mu S(k, \mu)$, of interest in themselves and important in what follows, are summarized in:

Lemma: The bailout subsidy $\mu S(k, \mu)$ has the properties:

(i) $S(k, \mu)>0, \forall k<1$ and $S(1, \mu)=0$;

(ii) $\mu S(k, \mu)$ is strictly increasing in $\mu$, for $\Phi<1$;

(iii) For $k<1$

$k S_{k}=-S+R_{k} \Phi[R(k)]<0$

and $\lim _{k \rightarrow 1} S_{k}(k, \mu)=0$; and

(iv) $S_{k k}(k, \mu)>0, \forall k<1$ if $R_{k k} \geq 0$.

Proof: Appendix 1.

Parts (i) and (ii) confirm that expected bailout costs are strictly positive and increase with the likelihood of bailout. Part (iii) shows that, as one would expect, a higher capital ratio-a reduction in borrowing — reduces the value of the bailout subsidy, and [in (2.11)] that it does

informed requires quite a leap of faith, asymmetric information of this type is not considered here, so as to focus on the inefficiencies associated with collapse and bailout.

${ }^{17}$ Kocherlakota (2010) refers to this as a 'risk externality.' 
so in two ways: first, it means that there is less borrowing to which the subsidy applies; second, by reducing the probability of bankruptcy it reduces the unconditional likelihood that bailout will happen. The consequence of this latter effect is that the marginal cost to the government of the bailout subsidy as the bank reduces its capital ratio, $-S_{k}$, exceeds its average cost, $(1 / k) S$. Consistent with this intuition, the seemingly reasonable assumption (maintained henceforth) that $R_{k k} \geq 0$ ensures convexity in $k$. Figure 1 illustrates.

\section{Figure 1}

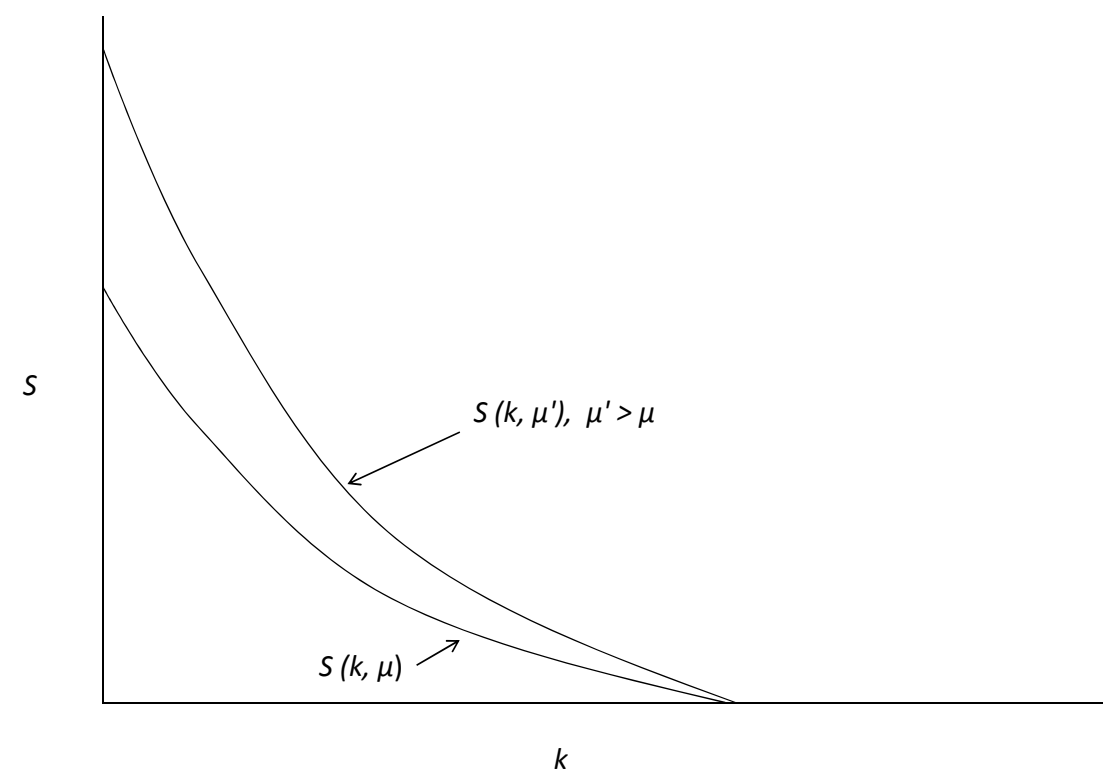

To provide further intuition for this subsidy, and some sense of its possible magnitude, denote by $\rho^{\prime}$ the return $\rho(k, 0)$ that the bank would have to pay if there were no prospect of bailout. Setting $\mu=0$ in (2.7), this is defined by

$$
\zeta D=\rho^{\prime} D\left\{1-\Phi^{\prime}\right\}+L \int_{-\infty}^{R^{\prime}} r \phi(r) d r
$$

where $R^{\prime}$ and $\Phi^{\prime}$ denote the corresponding critical return and risk of failure. Comparing this with (2.7), and assuming for simplicity that $\int_{R}^{R^{\prime}} \phi(r) d r \approx 0$, gives

$$
K S(k, \mu) \approx D\left\{\rho^{\prime}\left(1-\Phi^{\prime}\right)-\rho(1-\Phi)\right\}
$$

The subsidy is thus closely related to $\rho^{\prime}-\rho$, which is the reduction in the bank's borrowing rate consequent on the possibility of bail out. Estimates have put this in the range of 10-50 
basis points, and commonly around $20 .{ }^{18}$ Equation (2.13) shows that the reduction in borrowing costs on actual borrowing, $\left(\rho^{\prime}-\rho\right) D$, is not an exact measure of the value of the bailout subsidy (because it only benefits the bank when it does not fail, and also changes the likelihood of that happening). But it is likely to be reasonable approximation.

\section{The collapse externality}

Failure of the bank is assumed potentially to generate wider social costs, additional to the cost $\delta K$ borne by owners and the fiscal cost implicit in $S$. These, however, do not arise if creditors are fully bailed out, reflecting the common rationale for bailout as a circuit breaker, forestalling firesale and domino effects that trigger wider failures and damage to the real economy. ${ }^{19}$ The protection of creditors of AIG, Bear Sterns, and RBS, for example, reflected fear of the wider fallout from its collapse; the collapse of Lehman, on the other hand, was an instance of the damage that unmitigated failure of a systemically important institution can cause. To capture this, the expected wider social externalities are taken to be $(1-\mu) \Delta K$, with $\Delta \geq 0$. The magnitude $\Delta$ of this collapse externality is taken as exogenous in what follows.

This is a considerable simplification. A more complete treatment might specify $\Delta$ as an increasing function $\Delta[\theta(\alpha)]$ of the institution's systemic importance $\theta$, in turn dependent on some vector $\alpha$ of its own and, potentially, other institutions' attributes and decisions. ${ }^{20}$ Optimal corrective policy would then condition partly on $\alpha$, complementing action on $k$ to reduce the probability of failure occurring by reducing the social damage when it does. Putting flesh on these generalities, however, is not easy. There is some agreement on key features associated with systemicness: IMF, FSB, and BCBS (2009), for instance, stress size, interconnectedness, and the (un)availability of substitutes to the services provided by the institution. And there are ideas on its quantification, such as the CoVaR measure of Adrian, Tobias, and Markus Brunnermeier (2009). ${ }^{21}$ The conceptual and practical subtleties of these measures, however, can make it hard to relate them to individual institution's choices. Some

\footnotetext{
${ }^{18}$ See Baker and McArthur (2009), Haldane (2009) and, for a review and extension of the evidence, IMF (2010a).

${ }^{19}$ In practice, the decision to bail out an institution may reflect considerations other than the avoidance of wider social damage, such as regulatory capture, the impact of lobbying or the view of large financial institutions as 'national resources': see, for instance, Shull (2010).

${ }^{20}$ It might also depend on other aspects of policy not addressed here: one thrust of current regulatory reform efforts, for instance, is to reduce $\Delta$ by strengthening resolution frameworks so as to facilitate the orderly winding down of systemically important institutions. Since resolution mechanisms are costly, a further rationale for a charge on financial institutions is in order to pay for them: see IMF (2010a).

${ }^{21}$ This measures the systemicness of an institution as the difference between the value at risk (VAR) of the overall financial system when that institution is in distress and its unconditional VAR.
} 
aspects, moreover, reflect features that are beyond the sole control of individual institutions, and so may be hard to address through tax measures. As is intuitively evident with CoVaR, for instance — and demonstrated by Acharya (2009) — the correlation between the return on assets held by one institution and those held by others is important; and one institution's interconnectedness may depend on the interconnectedness of those with which it deals. Characterizing these notions of systemicness is very much work in progress. Acharya et al. (2010) proceed by assuming that the externality in the event of systemic failure depends on the aggregate shortfall of capital from some target, and the approach here is in similar spirit. It provides a crude but convenient way to explore key issues in the design of and choice between tax and regulatory approaches. ${ }^{22}$

\section{Social Welfare}

The government, we assume, attaches full weight to the costs incurred by owners in the event of failure. It also faces costs of $\lambda \geq 0$ in raising the revenue needed to finance bailout, reflecting not only deadweight losses in the wider tax system but also perhaps a lesser social value of transfers to bank owners than of transfers from general taxpayers. The government thus evaluates policy by

$$
W=-\Phi(R)[\delta+(1-\mu) \Delta] K+\int_{-\infty}^{\infty}\{r L-\zeta D\} \phi(r) d r-\lambda \mu K S
$$

Comparing this with the bank's objective function in (2.8), the difference arises from the two externalities discussed above: for collapse and for bailout, each weighted by the probability of their arising.

\section{Private ANd Social Optima}

This section characterizes the inefficiencies, in the form of excess risk-taking, that arise in the absence of intervention and explores the appropriate corrective tax policy.

\section{A. Private Optimization}

It will be convenient-both analytically and to relate the analysis to the common focus of regulatory policy - to take the bank's choice variable to be the capital ratio $k$; since (until the next section) total equity capital $K$ is fixed, this is equivalent to choosing assets $L$ or, from

\footnotetext{
${ }^{22}$ A link between size and systemicness could easily be encompassed in the framework here by allowing $\Delta$ to be some potentially nonlinear function of $K$ : this would simply replace $\Delta$ in the marginal conditions for social optimality below by $\Delta+\Delta^{\prime} / K$. It is unclear, however, that simply replacing a single institution by multiple clones in itself reduces systemic risk.
} 
(1), borrowing $D$. Dividing (2.8) by $K$ and using (2.1), the bank's maximand expressed in these terms becomes

$$
p(k, \mu) \equiv \frac{P}{K}=-\Phi[R(k, \mu)] \delta+\int_{-\infty}^{\infty}\left\{r\left(\frac{1}{k}\right)-\zeta\left(\frac{1}{k}-1\right)\right\} \phi(r) d r+\mu S(k) .
$$

The bank, we assume, recognizes the impact of its capital ratio on the rate at which it can borrow, while taking the probability of bailout as given.

Differentiating in (3.1), the necessary condition on the bank's choice of capital ratio is

$$
p_{k}(k, \mu) \equiv-\phi(R) \delta R_{k}-\left(\frac{1}{k}\right)^{2} \int_{-\infty}^{\infty}(r-\zeta) \phi(r) d r+\mu S_{k}(k)=0,
$$

where, from (2.10),

$$
R_{k}=-\rho+\rho_{k}(1-k)<0 .
$$

The bank thus trades off the beneficial effects of a higher capital ratio in reducing the chances of failure against the adverse effects through contracting a profitable loan portfolio and reducing the value of the implicit bailout subsidy.

The second order condition requires negativity of

$$
p_{k k}=-\Omega \delta+2\left(\frac{1}{k}\right)^{3} \int_{-\infty}^{\infty}(r-\zeta) \phi(r) d r+\mu S_{k k}
$$

where

$$
\Omega \equiv \phi^{\prime}\left(R_{k}\right)^{2}+\phi R_{k k} .
$$

It is reasonable to suppose the density of returns to be increasing in the low tail associated with failure, and the maintained assumption that $R_{k k} \geq 0$ then ensures that $\Omega>0$. The second order condition can be satisfied, however, only if the effects through this term are strong enough to outweigh two others shown in (3.4). The first of these, through the integral, reflects the mechanical feature that increasing the capital ratio requires a smaller reduction in profitable loans the higher is the initial ratio. ${ }^{23}$ The second is the convexity of the bailout subsidy discussed above: the higher is the initial capital ratio, the lower is the private cost, in terms of bailout subsidy foregone, of increasing it further.

\footnotetext{
${ }^{23}$ Since $L=(1 / k) K, d L=-\left(1 / k^{2}\right) K . d k$.
} 
That the bank's maximand may not be globally concave is analytically inconvenient. The potential that it implies for small changes in the environment to lead to large shifts between stable equilibria is resonant, however, of the notion of financial markets as inherently unstable.

\section{B. Social Optimality}

Dividing (2.14) by $K$ and using (2.1), social welfare, viewed as function of the capital ratio, is

$w(k, \mu) \equiv-\Phi(R(k, \mu))[\delta+(1-\mu) \Delta]+\int_{-\infty}^{\infty}\left\{r\left(\frac{1}{k}\right)-\zeta\left(\frac{1}{k}-1\right)\right\} \phi d r-\lambda \mu S(k, \mu)$.

For the moment - this will be relaxed later - the bailout probability $\mu$ is assumed not to be a choice variable for the government, but fixed at some arbitrary level. Attention thus focuses on the socially optimal capital ratio, the necessary condition being

$$
w_{k}(k, \mu) \equiv-\phi(R)[\delta+(1-\mu) \Delta] R_{k}-\left(\frac{1}{k}\right)^{2} \int_{-\infty}^{\infty}(r-\zeta) \phi(r) d r-\lambda \mu S_{k}(k) .
$$

The interpretation is straightforward: comparing (3.7) with (3.2) gives

$$
w_{k}=p_{k}-\phi(R)(1-\mu) \Delta R_{k}-(1+\lambda) \mu S_{k}(k)=0,
$$

so that the necessary condition for social optimality differs from the private analogue in reflecting the marginal impact of the capital ratio on the collapse and bailout externalities. (The second order condition is again problematic, though somewhat less so than for the private optimization, since the term in $S_{k k}$ is in this case conducive to its satisfaction). The possibility of these externalities arising could be entirely eliminated by inducing the bank to hold so much capital that it can never fail, but this cannot be optimal: it is readily shown that $\Phi(R)>0$ at any social optimum, ${ }^{24}$ the social cost of the loans foregone in making failure impossible being too high. The problem is not that banks fail, but that they may do so too often.

\footnotetext{
${ }^{24}$ Given the continuity of $w$, this follows on noting, recalling (2.2) and part (iii) of the Lemma, that (3.7) implies
}

$$
\lim _{k \rightarrow 1} w_{k}(1, \mu)=-\int_{-\infty}^{\infty}(r-\zeta) \phi(r) d r<0
$$




\section{Inefficiency and Corrective Taxation}

It is intuitively clear from the discussion of the collapse and bailout externalities above that the bank will choose a capital ratio that is too low from the wider social perspective. This is verified by setting $p_{k}=0$ in (3.8) to find

$$
w_{k}=-\phi(R)(1-\mu) \Delta R_{k}-(1+\lambda) \mu S_{k}>0 .
$$

and hence:

PROPOSITION 1: In the absence of intervention, and whatever the probability of bail out, the capital ratio is inefficiently low and, correspondingly, the probability of failure inefficiently high.

This inefficiency, arising from the social costs of collapse and the expected costs of bailout, provides a rationale for policy intervention. The question is what form it might best take.

One form - the traditional approach to dealing with financial sector externalities-is a regulatory requirement that the bank restrict its borrowing so as to have exactly the socially optimal capital ratio $k^{*}$; or, mimicking practice more closely, impose $k^{*}$ as a minimum.

An alternative is taxation. This is most conveniently formulated here as a (potentially nonlinear) tax/subsidy $T(k)$ on the capital ratio, but (as will be seen) is equivalent in effect to a tax on borrowing or assets. ${ }^{25}$ The bank's maximand then becomes $p(k, \mu)-T(k) .{ }^{26}$ and social welfare is now given by

$$
w(k, \mu)=p(k, \mu)-\Phi(R(k, \mu))(1-\mu) \Delta-(1+\lambda) \mu S(k)+\lambda T(k)
$$

Differentiating in (3.10), the bank, in equating $p_{k}$ to the marginal tax rate $T^{\prime}$ will be led to choose the socially optimal capital ratio $k^{*}$ only if ${ }^{27}$ the tax is set as in:

PROPOSITION 2: Corrective taxation requires a marginal subsidy to the capital ratio (or equivalent marginal tax on borrowing or lending) of

\footnotetext{
${ }^{25}$ An alternative tax-type approach is to impose an ex post clean-up charge after damage has occurred. Shavell (2010) provides a general comparison between this and the ex ante approach here, and IMF (2010) discusses the difficulties of the latter in the specific context of financial sector failures.

${ }^{26}$ This reflects an assumption that the tax does not affect the probability of bankruptcy. Other than the usual device of assuming revenue to be returned to the bank as a lump sum, this could be rationalized by supposing creditors' claims to be senior to the tax authorities'; but the additional complexity bring few additional insights.

${ }^{27}$ The second order condition on the bank's problem now reflects also the shape of the tax schedule, with convexity (likely to be optimal, as seen shortly) conducive to its satisfaction.
} 


$$
-T^{\prime}(k)=-(1-\mu)\left(\frac{\phi(R) R_{k} \Delta}{1+\lambda}\right)-\mu S_{k}>0
$$

This is straightforward, with the two components of the corrective subsidy correcting for each of the possible consequences of failure identified above, with weights reflecting the probability of their arising. The first is addressed to the collapse externality, inducing a higher capital ratio that reduces (by an amount $\phi(R) R_{k}$ ) the probability of its arising, with this element of subsidy scaled down to the extent of the marginal cost of raising the necessary finance. The second term counteracts the bank's incentive to increase the bailout subsidy by setting a lower capital ratio than it otherwise would, an aspect of corrective policy stressed, for example, in the informal treatments of Weder di Mauro (2009) and Kocherlakota (2010). ${ }^{28}$

\section{Calibrating the Optimal Tax on Borrowing}

To get a sense of the possible magnitude of the corrective subsidy to the capital ratio called for by Proposition 2, broadly comparable to bank taxes of the kind introduced in the United Kingdom and elsewhere or under consideration, it is useful to reformulate it as a $T^{D}(D)$ on borrowing $D$. Viewed as a function of $k$, tax paid is then $T^{D}(D)=T^{D}(K((1 / k)-1))$, so that the implied marginal tax on $k$ is $-T^{D^{\prime}} K(1 / k)^{2}$. To implement the optimum, the marginal tax on borrowing must therefore be such that

$$
T^{D^{\prime}}=-k^{2} T^{\prime}>0
$$

where $T^{\prime}$ is as in Proposition 1.

Consider first the optimal tax on borrowing to address the collapse externality: the first element of the corrective tax in Proposition 2. Estimates of the probability of crisis $\Phi(k)$ [reviewed in Annex 2 of BCBS (2010)] suggest it to be strongly convex in the capital ratio. In this case, with $\mu=0$, a lower bound on the corrective tax on borrowing is given by ${ }^{29}$

$$
T^{D^{\prime}}(k) \geq\left(\frac{\Phi(k) k^{2}}{(1+\lambda) \bar{K}}\right) \bar{\Delta}
$$

\footnotetext{
${ }^{28}$ Acharya et al. (2010) derive an optimal corrective tax with an additive structure similar to that in (3.11), with the latter term reflecting the additional structure on the nature of the systemic externality mentioned above.

${ }^{29}$ That this is a lower bound follows on using in (3.11) both the implication of (3.3) that (since $\rho_{k}<0$ )

$-R_{k}>\rho$ and $\phi k \geq \Phi$.
} 
where $\bar{K}$ and $\bar{\Delta} \equiv \Delta K / Y$ denote respectively bank capital and collapse costs in percent of GDP. For the United Kingdom, which has a large banking sector, bank capital is around 10 percent of GDP; and reasonable figures for cumulative output loss from systemic collapse might be, recalling the discussion above, 63 and 100 percent of GDP. Suppose, for simplicity, that the marginal cost of public funds is zero. ${ }^{30}$ The other element in (3.13), the probability of collapse $\Phi(k)$, varies with the capital ratio. For the five largest banks in the United Kingdom, the first row of Table 1 shows estimates of the (annual) probability of failure $\Phi(k)$ reported in BCBS (2010), calculated using a Bank of England model. For the two alternative collapse costs $\bar{\Delta}$, the third and fourth rows of Table 1 reports the optimal marginal tax on bank borrowing at different capital ratios.

\section{Table 1. Optimal Corrective Tax on Borrowing to Address Collapse Externality}

\begin{tabular}{ccccc}
\hline & \multicolumn{5}{c}{ Capital ratio, $k$} \\
\cline { 2 - 5 } & 6 & 8 & 10 & 12 \\
\cline { 2 - 5 } Probability of crisis (annual), $\Phi(k)$ & 12.8 & 2.6 & 0.9 & 0 \\
Collapse externality $(\mu=0):$ & & & 6 & 0 \\
$\Delta=63$ & 32 & 12 & 9 & 0 \\
$\Delta=100$ & 51 & 16 & 2 & 0 \\
\hline
\end{tabular}

Note: Tax in basis points, rest in percent.

Two features stand out. The first is that the (lower bound on the) optimal tax is in some cases quite large, certainly much larger than those generally adopted or envisaged: about 50 basis points in the more extreme of the circumstances shown. There is, it should be noted, an important difficulty of interpretation here, in that the model is of a single institution while the collapse cost estimates refer to the wider financial system. For an institution that is indeed systemically important, of course, the distinction is moot. Nevertheless, one might expect losses from isolated failures - to the extent that those can be imagined —as less than those from the system as a whole. This naturally reduces the optimal tax, though it plausibly remains significant: if damage is only 25 percent of GDP, for instance, it falls to 11 basis points at a capital ratio of 6 percent. The second and still more striking aspect of the results in Table 1 is the very strong variation of the optimal tax with the capital ratio (reflecting that of

\footnotetext{
${ }^{30}$ It may seem strange that in (3.13) a higher marginal cost of public funds, implying a higher valuation of tax receipts, implies a lower corrective tax. This is though a standard result in the optimal taxation of externalities, and captures the idea (see Bovenberg and de Mooij, 1994) that the tax worsens pre-existing (here unmodeled) distortions. A low distributional weight attached to bank owners, on the other hand, would in itself imply $\lambda<0$.
} 
the probability of crisis): even with potential output costs of 100 percent of GDP, the optimal tax is negligible at a capital ratio of 12 percent. The implication is that the optimal borrowing tax is likely to be highly nonlinear, increasing rapidly as capital ratios fall so low as to rapidly increase the likelihood of crisis.

Consider now the corrective taxation in respect of the bailout externality. Taking the extreme case in which $\mu=1$, the optimal tax on borrowing is shown in Appendix 2 to be approximated very simply as

$$
T^{D^{\prime}} \approx \zeta \Phi(k)
$$

The final row of Table 1 tabulates values for a risk-free rate $\zeta$ of 5 percent. This suggests that the bailout externality calls for a corrective tax of the same order of magnitude as that appropriate for the collapse externality (though falling more rapidly with the capital ratio), rising to 40 basis points at the lowest capital ratio shown. With the overall charge in Proposition 2 being, broadly, ${ }^{31}$ an average of the two weighted to reflect the probability of bailout $\mu$, it may be that it makes relatively difference to the proper tax rate how likely bailout is perceived to be.

\section{E. Revenue}

It is of interest too to consider the revenue raised by a corrective tax of the kind in Proposition 2. Strictly, of course, this is indeterminate: Proposition 1 ties down the marginal tax rate, not the average. It is also of little relevance in the sense that revenue-raising is not the primary motivation of corrective taxation. A powerful strand of thought in the public debate on financial sector taxation, however, is that the financial institutions themselves should 'pay' for the damage that their collapse or bailout causes the rest of society. Leaving aside the incidence issues raised by this form of the idea that the 'polluter should pay' (as an aspect of fairness, not necessarily efficiency), this makes it useful to know whether revenue from corrective taxation would be sufficient to cover the expected costs of direct fiscal support and bail out.

Suppose then that correction is implemented in the form of a proportional $\operatorname{tax} T^{D}$ on borrowing by the bank. Then, relating the revenue associated with each component of the optimal tax to the costs of the externality to which it is addressed:

PROPOSITION 3: For the optimal corrective proportional tax on borrowing, revenue raised (a) By the bailout related part more than covers the expected fiscal cost of bailout, $\mu S K$.

\footnotetext{
${ }^{31}$ Not precisely, because the approximation in (3.14) presumes $\mu=1$.
} 
(b) By the systemic part of the tax more than covers the expected cost of the systemic externality, $(1-\mu) \Phi \Delta K$, if

$$
-\left(\frac{\partial \ln [\Phi(r)]}{\partial \ln (r)}\right)\left(\frac{\partial \ln R(k, \mu)}{\partial \ln k}\right)>\frac{1+\lambda}{1-k}
$$

Proof: Appendix 3.

That the bailout component more than pays for expected bailout is a consequence of the convexity of $S(k)$ discussed above. The implication is that the corrective tax on borrowing is not equivalent to an actuarially fair insurance premium. This is because in increasing its borrowing, a bank not only expands the volume of debt to be bailed out but, in making failure more likely, also increases the chance that such a bailout will occur. The bailout subsidy is actuarially fair only if the rate at which the bank borrows is independent of its capital ratio — as would be the case if creditors were to be bailed out for sure, or in the case of archetypal small depositors who take no account of the possibility of default.

The reason for the ambiguity in part (b), on the other hand, is clear: the corrective tax reflects the impact of a marginal increase in the capital ratio on the likelihood of failure, whereas expected social damage reflects that likelihood itself. Few sharp results are available, even for particular functional forms, the issue turning [the left of (3.15)] on the elasticity of the likelihood of failure with respect to the capital ratio. Both components of this elasticity can be expected to exceed unity (that relating to the distribution function, because of its likely convexity; that relating to the critical return, because [recalling (3.3)] of the sensitivity of the borrowing rate). With a sufficiently low marginal cost of public funds and sufficiently high optimal capital ratio, the optimal corrective tax is then sure to cover the expected costs of collapse. The likely low value of the right of (3.15) suggests, albeit tentatively, that this may indeed be the more likely case more generally. If so, then, with the corrective bailout element more than meeting the expected fiscal costs of direct government support, the case for an additional charge on the financial sector on 'polluter pays' ground is correspondingly weak.

\section{EXTENSIONS}

This section extends the analysis above in two directions, allowing the government to choose its bailout policy and the bank to decide the level of its equity capital.

\section{A. Endogenizing the Bailout Decision}

The assumption that the probability of bailout is fixed at some arbitrary level denies what is in practice a critical policy choice. Clearly too the nature of that choice will differ according to whether the government can or cannot commit to its bailout policy in advance of the realization of the return on the bank's assets. 
Supposing first that the government can and does commit to the likelihood of bailout, it will then choose $\mu$ to maximize $w(k, \mu)$, the necessary condition for this being, from (3.6),

$$
w_{\mu}(k, \mu)=\Phi \Delta-\phi R_{\mu}[\delta+(1-\mu) \Delta]-\lambda\left\{S+\mu S_{\mu}\right)=0
$$

This is a straightforward trade-off between, on one hand, the benefits that an increased likelihood of bailout brings in reducing the likelihood of incurring the collapse externality (by allowing the bank to borrow more cheaply) and, on the other, the expected fiscal cost of bailout. One implication of note is that, since the latter effect vanishes if $\lambda=0$ :

PROPOSITION 4: In the full commitment case, if the marginal efficiency cost of taxation is zero then it is optimal to bail out with probability one. More generally, the optimal probability of bailout $\mu$ may lie between zero and unity.

This runs starkly counter to the connotation of bailouts as something uniformly undesirable: this is especially clear when, as in the proposition, there are no distortionary (or distributional) costs of financing them: they are then just a transfer, serving to avert the collapse externality without doing any damage. Bailout is then in effect a first-best instrument for addressing the inefficiencies associated with the possibility of failure. More generally, even when there is some social cost to financing bailouts, it will generally not be optimal to commit to never bail out.

It is perhaps more plausible to suppose, however, that the government cannot commit to its bailout policy, but must decide conditional on the realization of $r$. When this is below the critical level $R$, its options are to either allow unmitigated failure, resulting in social costs of $\Delta K$, or to bail out, incurring distortionary costs of $\lambda(\rho D-r L)$ in raising tax revenue to top up the residual value of assets so as to leave creditors whole. ${ }^{32}$ Comparing the two, bailout is preferable if and only if

$$
r \geq \tilde{R} \equiv \rho(1-k)-\left(\frac{k \Delta}{\lambda}\right)
$$

The government will thus bail out only if the failure is not too spectacular: when $r<\tilde{R}$, the bank is too big — or too unlucky or undercapitalized - to save; a possibility whose practical importance is stressed by Demirgüç-Kunt and Huizinga (2010).

In the knowledge of this policy, the return $\rho(k)$ required by the banks' creditors will now be given not by (2.7) but by

\footnotetext{
${ }^{32}$ The assumption is maintained that creditors take no haircut in the event of bailout.
} 


$$
\zeta D=\rho D\{1-\Phi(\tilde{R})\}+L \int_{-\infty}^{\tilde{R}} r \phi(r) d r
$$

which, used in (2.6), gives

PROPOSITION 5: When the government cannot commit to its bailout policy, the bank's maximand is as in (2.8) above but with $\mu K S(k, \mu)$ replaced by

$$
K \Gamma(k) \equiv \rho(k)\left(\frac{1}{k}-1\right)[\Phi(R)-\Phi(\tilde{R})]-\left(\frac{1}{k}\right) \int_{\tilde{R}}^{R} r \phi(r) d r \geq 0
$$

The value to the bank of prospective bailout term thus becomes $\Gamma(k)$, latter reflecting the difference that now its creditors are bailed out only for realizations of $r$ between $R$ and $\widetilde{R}$. Much of the earlier analysis can be recast in these terms. It is readily verified, for instance, that (with similar elements of approximation) $\Gamma$ can also be interpreted as the value of a subsidy to the borrowing rate, just as in (2.13). And the optimal corrective tax will be as in Proposition 2, the second component now being $-\Gamma_{k}$ rather than $-S_{k}$.

There is, however, a potentially important difference: whereas $\mu S$ is unambiguously decreasing in $k$, the same does not seem to be assured for $\Gamma$. For given $R$ and $\tilde{R}$, it is easily seen that $\Gamma$ is similarly decreasing in $k$; and it can also be shown that $\Gamma$ is locally independent of $R$. It can also be shown, however, that $\Gamma$ is decreasing in $\tilde{R}$. Through this route, recalling (4.2) a higher capital ratio tends to increase the value of the bailout subsidy. Intuitively, when the government cannot commit to its bailout policy, one of the considerations entering the bank's choice of capital ratio is that a higher capital ratio makes it cheaper for the government to bailout creditors, and hence more likely that it will do so-which acts in the direction of its choosing a higher capital ratio than otherwise. One cannot rule out the possibility, it seems, that this effect will dominate, so that $\Gamma_{k}>0$; in which case, the corresponding component of the optimal corrective tax on borrowing will be negative.

\section{B. Taxing Bank Equity}

The bank's equity capital $K$ has so far been taken as given. Allowing it to be chosen by the bank provides another potential dimension for corrective policy. To see what form this might take, suppose - arbitrary but simple — that the bank faces an upward-sloping supply of equity, suppliers requiring to receive $\gamma(K)$ to supply $K$, with $\gamma$ increasing and convex. With the government taxing this return at rate $\tau$, the bank's maximand becomes (reverting now to the model of sections II and III, and recalling (3.1)) $P=p(k, \mu) K-(1+\tau) \gamma(K)$. It thus chooses $K$ so that

$$
p=(1+\tau) \gamma_{k}(K)
$$


Assuming for brevity that $\lambda=0$, social welfare, similarly, is now $w(k, \mu) K-\gamma(K)$, so that at an optimum $w=\gamma_{k}(K)$. Combining these observations and finding $p-w$ from (3.1) and (4.5):

PROPOSITION 6: Given optimal correction of the capital ratio, social optimality requires that bank equity be taxed at the rate

$$
\tau=\left(\frac{1}{w}\right)[\Phi(1-\mu) \Delta+\mu S]>0
$$

Bank equity should thus be subject to a strictly positive tax so long as either externality is operative-simply because both are more costly the larger is the bank. A fully optimal policy thus comprises a tax on the bank's equity to reduce the magnitude of the social costs arising from its collapse or bailout, and a tax on its borrowing (or equivalent) to correct for the bank's tendency, whatever its overall size, to accept a socially excessive risk of its own failure.

\section{Comparing TAX AND Regulation}

Instrument choice has, so far, been taken as given. There is, however, an obvious (and, in practice, dominant) alternative to corrective taxation: capital regulation, in the form of restrictions on permissible capital ratio. This section assesses, within the framework of Sections II and III above, the relative merits of taxation and capital regulation along three key dimensions. For simplicity, it is assumed — until the final subsection — that the tax instrument on borrowing is a simple proportional one.

\section{A. Non-Convexity}

The possibility that the bank's objective function may not be globally concave creates the familiar difficulty that it may not be possible to implement the first best by linear taxation. It means, for instance, that the marginal private cost of increasing the capital ratio, given by

$$
C_{k} \equiv-p_{k}=\phi(R) \delta R_{k}+\left(\frac{1}{k}\right)^{2} E[\zeta-r]-\mu S_{k}
$$

will be as in Figure 2. If the first-best is at $k^{*}$, for instance, this cannot be decentralized by setting a subsidy to the capital ratio as in Proposition 2: the bank would instead choose a capital ratio of (depending on the precise shape of $c_{k}$ ) $k^{A}$ or $k^{B}$. 


\section{Figure 2}

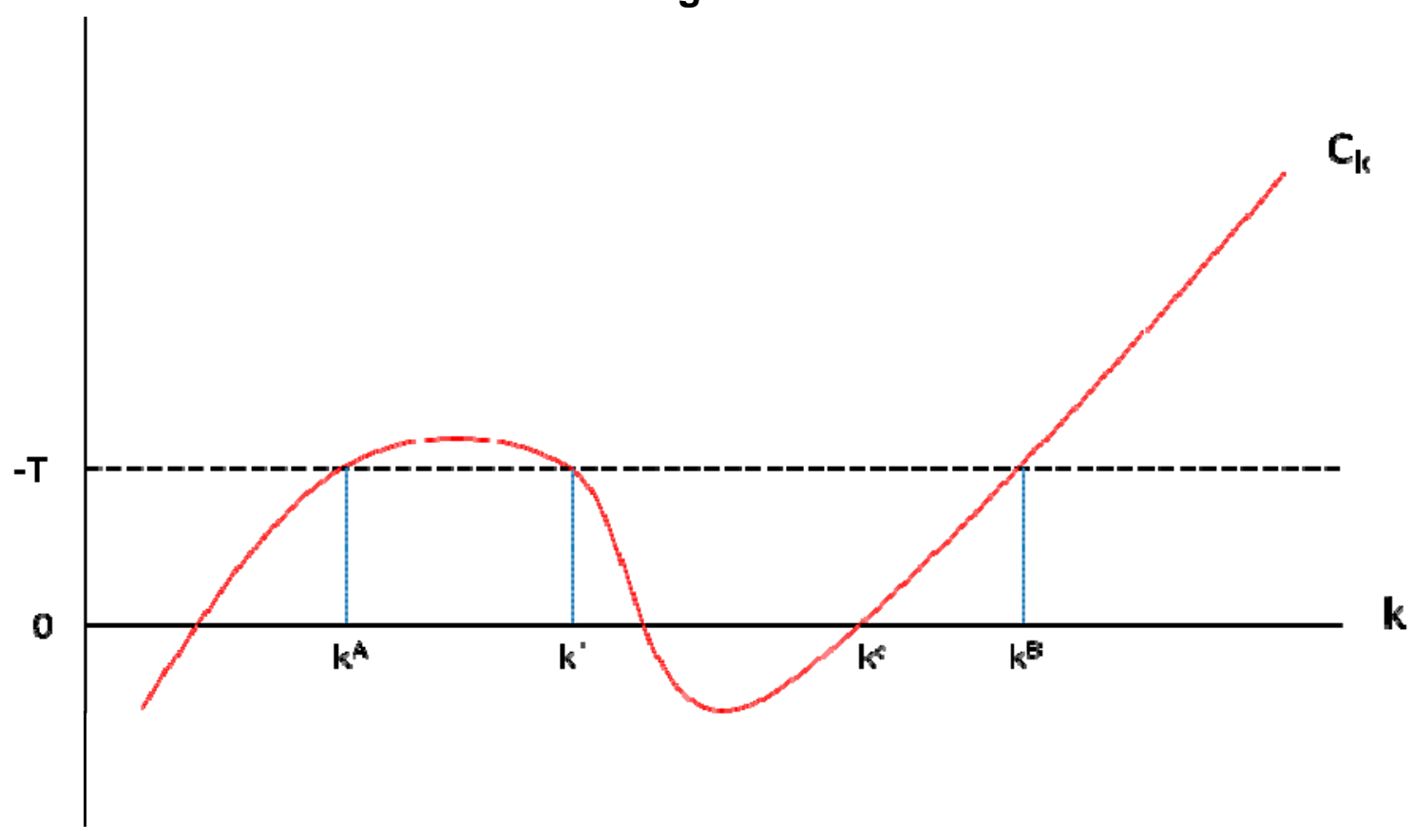

Regulation in the form of a requirement that capital of exactly $k^{*}$ be held clearly avoids this difficulty. Regulation in the weaker, standard form of a minimum capital requirement, however-requiring that at least $k^{*}$ be held—may not: forced to hold no less than $k^{*}$, the bank might choose instead to hold strictly more, at $k^{C}$. Nonetheless, regulation offers clear advantages over taxation when non-convexity is a concern-as is inherently the case in the model above. This is especially so when avoiding very low capital ratios is particularly important.

\section{Uncertainty}

The analysis so far has abstracted from uncertainty in the sense that both bank and policymaker have been perfectly informed as to the environment in which policy will take effect: thus while the return on assets is stochastic in the analysis above, its distribution is not. Suppose, however, that while information remains symmetric between bank and government, policy — whether tax or regulatory — must be made before the environment to which the bank will react is fully known to government, and cannot be conditioned on all relevant features of that environment. Specifically, suppose the distribution of returns $\Phi$ becomes known only after policymakers must act—circumstances may turn out better or worse than they expected—but before the bank makes it decisions. In general, neither taxation nor capital regulation will then achieve the ex post first-best. The question is whether the consequent policy errors will prove more costly under a tax-based approach 
(which allows banks to adjust the capital ratio to changing circumstances) or regulation (which does not, or at least restricts that adjustment). ${ }^{33}$

This is a problem of the general form addressed in Weitzman (1974). To cast it in the form of the analysis there, it is convenient to again take the tax policy instrument to be a proportional subsidy to the capital ratio, and to abstract from the revenue-raising aspect of the comparison by taking $\lambda=0$. Defining the marginal external benefit from an increase in the capital ratio to be (from (3.8))

$$
B_{k} \equiv w_{k}-p_{k}=w_{k}+C_{k}=-\phi(R)(1-\mu) \Delta R_{k}-\mu S_{k}
$$

it will be assumed now that $B_{k k}<0$ and $C_{k k}>0$ : the social optimum is then characterized by the intersection of a downward sloping marginal external benefit curve and an upward-sloping private marginal cost curve.

Suppose, for example, that there is a worsening in the outlook after policy has been set, in the sense that the expected return when the bank does not fail, $\int_{R}^{\infty} r \phi(r) d r$, turns out lower than expected (with $\Phi(R)$ unchanged): Figure 3 illustrates. From (3.2), and recalling that returns above the critical level $R$ do not affect the bailout subsidy, the private marginal cost curve $C_{k}$ shifts down, while $B_{k}$ is unaffected. Under the tax-based approach, and with the subsidy remaining at the rate $-T$ needed to secure the first-best capital ratio $k^{*}$ corresponding to initial expectations, the bank thus responds to the deterioration in the outlook by choosing a higher capital ratio, at $\bar{k}$. Under the regulatory approach, in contrast, if it had simply been required to hold $k^{*}$ it will evidently continue to do so. Moreover, if $k^{*}$ had instead been imposed as a minimum capital requirement the bank would still choose not to adjust: regulation is then forcing it to hold more capital than it wishes and, so long as $C_{k}\left(k^{*}\right)$ remains strictly positive, increasing the capital ratio will continue to be privately unprofitable.

\footnotetext{
33 The answer to the analogous question has played a key role, for example, in establishing a widespread preference for carbon taxation over cap-and-trade as instruments to address climate change: see for instance Pizer (2002).
} 
Figure 3

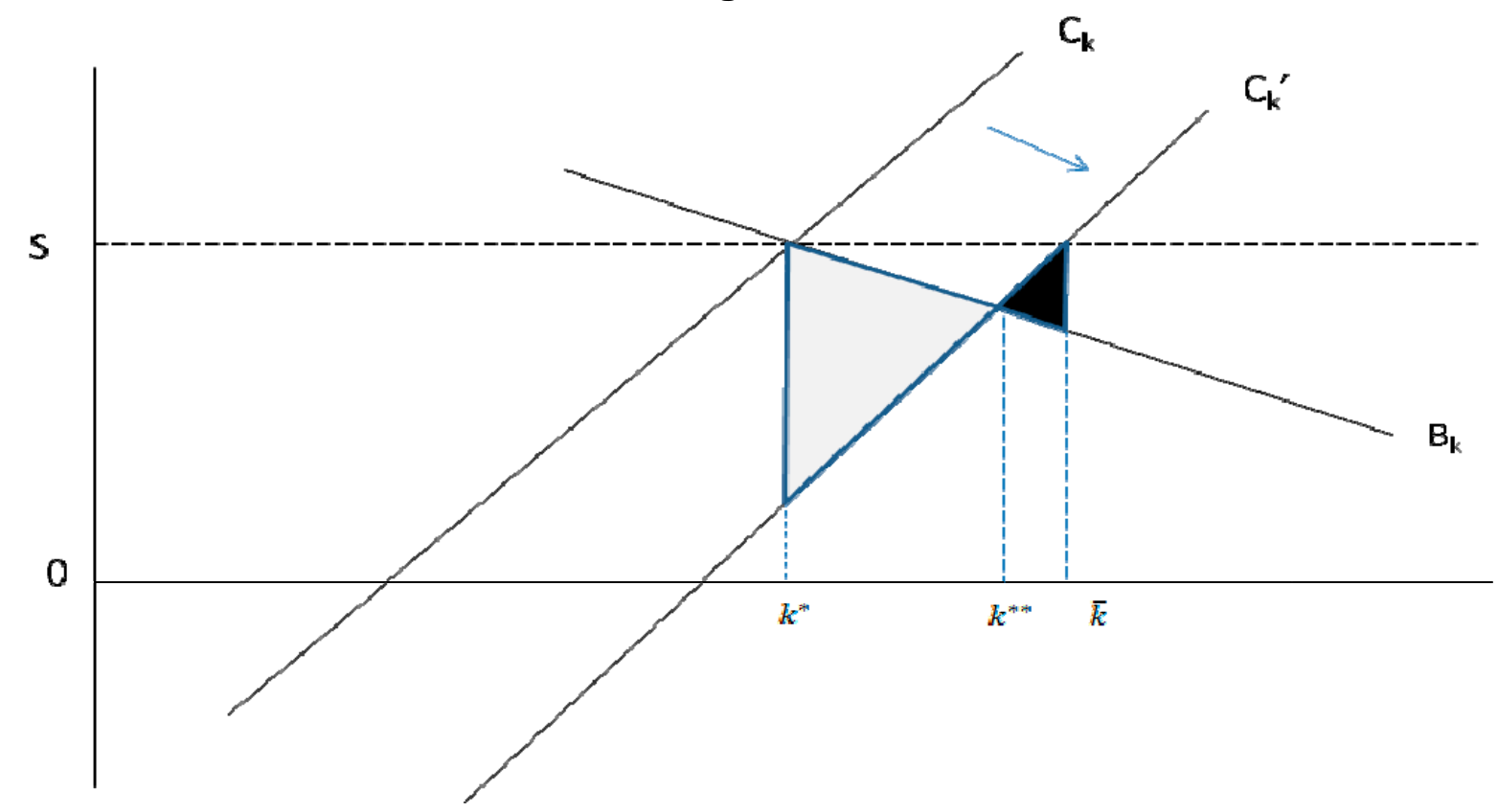

In this case, taxation has the merit of fostering prudence in responding to changing market circumstances. The danger, however, is of overreaction: the level now chosen by the bank, exceeds the new first-best at $k^{* *}$. Both approaches thus lead to some ex post inefficiency: the issue is whether that associated with regulation (the lighter triangle) is greater or less than that associated with taxation (the darker).

The key result of Weitzman (1974) for this class of problem is that, in the face of additive shocks to private marginal $\operatorname{cost} C_{k}$ that are uncorrelated to any shock to marginal external benefit $B_{k},{ }^{34}$ ex ante optimal regulation leads to less ex post inefficiency than does ex ante optimal taxation if and only if $\Sigma \equiv B_{k k}+C_{k k}<0$; that is, if the marginal excess burden curve is more steeply sloped than private marginal costs.. Differentiating in (5.2) and using (3.4), with $\lambda=0$, regulation is thus preferred if and only if

$$
\Sigma(k, \mu)=\Omega[\delta-(1-\mu) \Delta]-2\left(\frac{1}{k}\right)^{3} E(r-\zeta)-2 \mu S_{k k}<0 .
$$

The comparison is thus complex, with key roles being played by the magnitude of collapse costs $\Delta$ and the convexity of the bailout costs, $S_{k k}$. Some further insight is given by

\footnotetext{
${ }^{34}$ Shocks affecting only $B_{k}$ have no impact on the relative merits of taxation and regulation, since they do not affect the ex post outcome. This has the important implication here that uncertainty as to the size of the collapse externality $\Delta$ does not affect the choice between them.
} 
PROPOSITION 7: Suppose that $C_{k}$ is subject to an additive shock $v$ with $E[v]=0$. Then:

(a) It is sufficient for taxation to be preferred that $\Delta=S_{k k}=0$; and

(b) It is sufficient for regulation to be preferred that

$$
\delta<\min \left[\Delta, \mu S\left(\frac{4}{\Omega}\right)\right]
$$

Proof: Appendix 4

The intuition for part (a) is straightforward. When both $\Delta$ and $S_{k k}$ are (close to) zero, $C_{k}$ remains upward-sloping (by the second order condition (3.4)) but $B_{k}$ is everywhere zero. It is then optimal to allow private decisions to fully guide the capital ratio in response to changing circumstances, so that a (small) tax is better than a fixed capital ratio.

Suppose next that $\mu=0$, so that only the collapse externality applies. In this case, (5.3) gives the sharp result that it is sufficient for regulation to be preferred that $\delta<\Delta$; that is, that the social costs of collapse exceed the private costs of failure - a condition that one would certainly expect to be satisfied for systemic institutions. Intuitively, a low $\delta$ makes the bank's choice of capital ratio highly sensitive to taxation, while a high $\Delta$ means that small changes in the capital ratio can have large social consequences.

The case in which only the bailout externality applies $(\mu=1)$ is more complex. From (5.3), it is not the size of the bailout that matters, but that of $S_{k k} / \Omega$ : an increase in $S_{k k}$ makes $C_{k}$ flatter, because increasing $k$ is then less discouraged by the erosion of the value of the bailout subsidy, and makes $B_{k}$ steeper for the same reason, so tilting the preference toward regulation. The curvature of $S$, however, is complex. It is shown in proving part (b), nonetheless that $S_{k k}>2\left(S / k^{2}\right)$. While the presence of the term $\Omega$ means that the ranking of tax and regulatory approaches does not turn on a simple comparison of the size of the bailout subsidy and the private costs of failure (unlike the collapse externality case), the impression is again of regulation being more likely to dominate the larger is the externality at stake.

This framework has significant limitations, of course, as a guide to policy. These include the view of policy as a one-shot decision. There may be systematic differences, for instance, in the speed with which tax rates and regulatory requirements can be changed in the light of evolving circumstances. And in a less linear world than that formally modeled here, one might expect relative curvatures to vary over the cycle: in the relevant regions, the marginal external benefit curve may be relatively steep in bad times, and relatively flat in good times - calling perhaps for a combination of a minimum capital requirement to forestall the worst outcomes and a tax to guard against excessive optimism when the outlook is good. Indeed some nonlinear tax will generally dominate either quantity regulation or the proportional tax in the framework considered here (Roberts and Spence, 1976), with the 
preceding considerations suggesting a higher marginal rate on borrowing at lower capital ratios.

\section{Asymmetric information}

The superior information that banks are likely to have as to their own circumstances—such as the riskiness of their asset positions, the quality of their managers, and their willingness to accept to risk-poses challenges for both regulatory and tax approaches.

To see how these might affect the choice between them, and the refinements of policy it might call for, suppose now, adopting a stylized version of the model above, that the bank's maximand is of the form $p(k, a)$, where $a$-'ability,' though this is not the only interpretation-is some exogenous characteristic observed by the bank but not by the policy maker, and it is assumed that $p$ is strictly concave in $k$. Higher ability leads to higher profits, so $p_{a}>0$, and this effect is assumed to be stronger at lower levels of the capital ratio (perhaps because of the greater difficulty of monitoring the larger volume of loans this implies): thus, as a single-crossing condition, $p_{k a}<0$. The privately optimal capital ratio for a bank of type $a$ is thus given by

$$
p_{k}(\bar{k}, a)=0
$$

and is decreasing in $a$. Social welfare, in contrast, is given by $p(k, a)-\Lambda(k, a)$, whereagain following the broad structure of the model above, while shedding its details - the term $\Lambda$ can be thought of as an amalgam of collapse and bailout externalities; it is assumed that $\Lambda_{k}<0, \Lambda_{k k}>0$ and $\Lambda_{k a} \geq 0$. The first best capital ratio for type $a$, implicitly defined by

$$
p_{k}\left(k^{*}, a\right)=\Lambda_{k}\left(k^{*}, a\right)<0,
$$

is then readily shown to be decreasing in $a$. Clearly too $k^{*}(a)>\bar{k}(a)$, so that, matching the result above, the privately optimal capital ratio is, for any type, lower than is socially desirable.

Supposing there to be just two possible ability types, with $a_{1}>a_{2}$, it follows that the higher ability bank has the lower first-best capital ratio: in obvious notation, $k_{1}^{*}<k_{2}^{*}$. The question is how this allocation can be implemented. Figure 4 illustrates, showing the private maximand of each type as a function of $k$. 


\section{Figure 4}

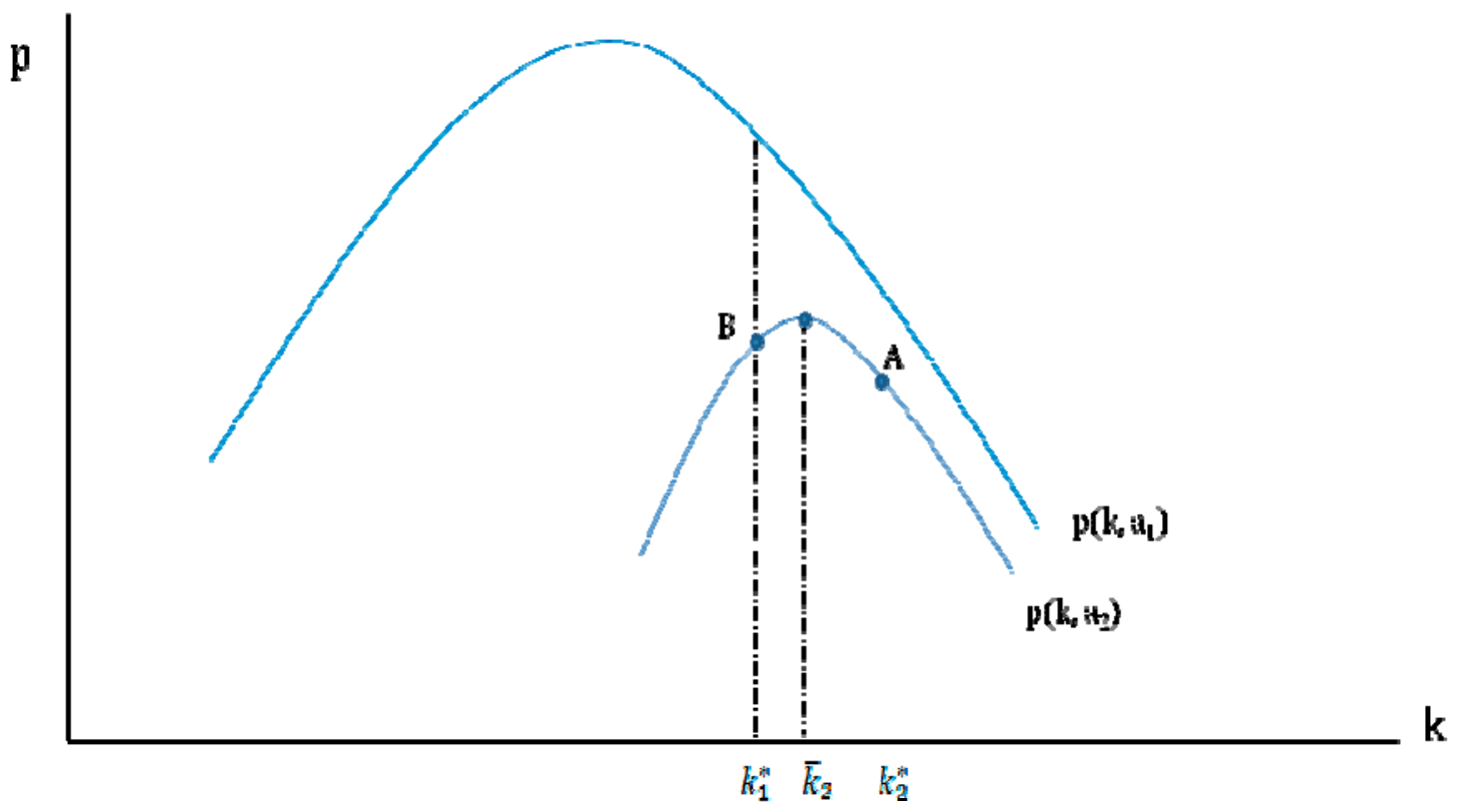

Regulation alone may well be unable to implement the first best, because of the self-selection constraints that need to be respected. If regulation takes the form of a minimum capital requirement, this will have to be set at $k_{1}^{*}$ in order to place the high ability firm at the appropriate capital ratio. But then the low ability bank is unrestricted in the neighborhood of its first best $k_{2}^{*}$, where its profits are strictly decreasing in $k$, and so will not choose that first-best: as drawn in Figure 3, it will instead choose its own private optimum $\bar{k}_{2}$.

An alternative strategy would be to offer banks a choice between capital ratios $k_{1}^{*}$ and $k_{2}^{*}$. The difficulty then arises that the low ability bank may prefer the low capital ratio intended for the high ability type to that intended for itself: ${ }^{35}$ this is the case in Figure 4, the payoff to the low ability type 2 being higher at $B$ than at $A$.

The figure also suggests, however, that the first can be implemented by levying a tax on any bank choosing the lower capital ratio, intended for the higher ability bank, that is large enough to deter the low ability from mimicking the high ability bank-but not so large as to induce the high ability bank to switch to the higher capital ratio that is socially appropriate for the low ability. This means finding an amount $T$ such that the self-selection constraints

$$
\begin{aligned}
& p\left(k_{2}^{*}, a_{2}\right) \geq p\left(k_{1}^{*}, a_{2}\right)-T \\
& p\left(k_{1}^{*}, a_{1}\right)-T \geq p\left(k_{2}^{*}, a_{1}\right)
\end{aligned}
$$

\footnotetext{
${ }^{35}$ The self-selection constraint will never bite for the high ability bank, since (5.6) and concavity imply that $p\left(k, a_{1}\right)$ is decreasing in $k$ above $k_{1}^{*}$, and $k_{2}^{*}>k_{1}^{*}$.
} 
are both satisfied. That such a $T$ can be found is established in:

PROPOSITION 8: The first-best can implemented by offering banks the choice between $\left(k_{1}^{*}, T\right)$ and $\left(k_{2}^{*}, 0\right)$, where

$$
T \equiv \max \left\{p\left(k_{1}^{*}, a_{2}\right)-p\left(\left(k_{2}^{*}, a_{2}\right), 0\right\} \geq 0 .\right.
$$

Proof: Appendix 5.

Implementation can thus be achieved by offering banks a menu that allows them to choose a capital ratio lower than some norm only on payment of an appropriate tax (or, equivalently, ${ }^{36}$ by setting a minimum capital ratio but providing an appropriate subsidy to banks choosing a higher ratio). The nonlinear tax schemes to which this result points are potentially complex though not obviously any more so than the differentiated capital requirements that have been proposed.

\section{CONCLUSIONS}

Though clearly highly simplistic, not least in slurring the distinction between the financial sector and its component financial institutions - the analysis here casts some light on the issues, neglected much more in principle than in practice, raised at the outset.

The corrective tax policy that emerges in the first part of the paper addresses, by a charge on the bank's borrowing (or equivalent tax on loans or subsidy on the capital ratio) two interrelated externalities at the heart of the crisis: those associated with the unmitigated failure of systemic institutions, and those implied by a perception that the government will bail out the bank's creditors in order to avoid these wider costs arising. The optimal tax has a simple additive form and seems likely to be highly nonlinear, increasing rapidly as the capital ratio fails to levels implying a significant chance of systemic failure. In these regions, illustrative calibrations suggest, an appropriate tax on borrowing might easily be in the order of 40 basis points. This is substantially higher than the 4-8 basis points of the taxes introduced in the United Kingdom and elsewhere in Europe, and proposed for the United States, though such rates do not look unreasonable for more times. Importantly, the bailout part of this corrective tax-mitigating the incentive for the bank to take on excessive risk in the expectation of public support in the event of failure-is optimally set above the insurance-like level that would recoup the expected fiscal cost of future bailouts. It also emerged, however, that optimal corrective bank tax policy likely depends on the extent to

\footnotetext{
${ }^{36}$ It is easily seen from (5.7) and (5.8) that only the difference in tax payments associated with the two capital ratios matters for self-selection.
} 
which the government is able to commit to its bailout policy: when it cannot, and may lack the resources to bail out creditors in the event of failure, the optimal tax seems likely to be lower than otherwise (since the bank then has an incentive to limit the cost of bailing it out).

This characterization of the optimal corrective tax leaves open the question of whether the same objectives might not be best pursued not by taxation but by imposing capital requirements. Non-convexities in bank payoff functions provide one possible advantage for a regulatory approach. Beyond that, two other sources of non-equivalence between taxation and regulation also seem potentially important. One is dealing with uncertainty, when policy must be set before the environment in which the bank operates is known. In this case, it was seen, regulation emerges very clearly as the preferred approach in dealing with the collapse externality if — as is plausibly the case for systemic institutions - the social costs of failure exceed the private costs. Matters are less straightforward when the bailout externality is the dominant concern: but it seems likely that regulation will again dominate, all else equal, if expected bailout costs are high enough. The other is asymmetric information. This likely requires that policy be more subtle than either linear taxation or a simple capital requirement. In the setting examined here, the first-best cannot be implemented by either, but can be achieved by allowing banks to hold less than some prescribed amount of capital contingent on paying an additional tax. This, in turn, can be thought of as a nonlinear tax with marginal rate increasing in the amount of bank borrowing. This is the same prescription, but for a different reason, as above. Theory, it seems, can readily rationalize a progressive tax on bank borrowing.

The analysis has abstracted from many features of reality that are important for practical policy design. But these seem in several respects likely to reinforce some of the main conclusions drawn here. One such consideration is the existence of preexisting tax distortions, the most immediately relevant of these being the bias that most corporate tax systems create towards the use of debt finance. A tax of the kind analyzed here could be seen precisely as tending to redress this bias in the banking sector, where it may prove particularly damaging, as a second-best alternative to the politically more difficult reform of the wider corporate tax. The practical question then is whether bank borrowing should be taxed more heavily than the analysis here implies, to redress the preexisting non-neutrality. Another key consideration, stressed by EEAG (2011), is that in practice any bank tax will not operate in the absence of any capital requirements - as, to fix ideas in a relatively unexplored area, has been assumed here- but in tandem with them. To the extent that the capital requirements bind, a (small) tax would have no impact on banks' behavior. In practice, however, banks generally seek to hold buffers above the minimum capital required, in which case a tax on borrowing will affect their borrowing decisions just as above (though their responsiveness to taxation may be weakened by their concern to avoid falling short of capital requirements). Analysis of the joint impact of regulation and taxation in such circumstances is left to future work. The results here, suggesting a marginal tax on borrowing that increases steeply at low capital ratios, point to possible merit in a strategy of combining both a capital requirement as 
protection in the most dangerous circumstance and a progressive tax on borrowing at higher capital ratios that accommodates banks' diversity and reflects the presence of tail risk even in more normal times. 


\section{Appendix 1. Proof of the Lemma}

Dividing (2.9) by $K$ and noting from (2.1) that $D / K=(1-k) / k$ gives

$$
\begin{gathered}
k S(k, \mu)=\rho \Phi(1-k)-\int_{-\infty}^{R} r \phi(r) d r \\
=\int_{-\infty}^{R(k, \mu)}(R(k, \mu)-r) \phi(r) d r .
\end{gathered}
$$

the second equality being from (2.10). Part (i) is immediate from (A1.2). For part (ii), note from (A1.2) and (2.10) that

$$
\begin{aligned}
S_{\mu} & =\left(\frac{1}{k}\right) \rho_{\mu}(1-k) \Phi \\
& =-\left(\frac{S \Phi}{1-\Phi(1-\mu)}\right)
\end{aligned}
$$

the second equality being from (F.2), and hence

$$
S+\mu S_{\mu}=\frac{(1-\Phi) S}{1-\Phi(1-\mu)} .
$$

For part (iii), differentiating in (A1.2) and canceling the terms in $\phi R R_{k}$ gives (2.11); the result follows on recalling that $R_{k}<0$. Part (iv) follows on differentiating in (A1.2) and rearranging to find

$$
k S_{k k}=-2 S_{k}+R_{k k} \Phi+\left(R_{k}\right)^{2} \phi\left(r^{*}\right) .
$$




\section{Appendix 2. Derivation of (3.14)}

With $\mu=1$, the optimal tax on $k$ is $T^{\prime}=S_{k}$. Substituting for $S$ in (2.11) from (2.13), making the approximation $\Phi^{\prime} \approx \Phi$, this is

$$
T^{\prime}=-\left(\frac{D}{k K}\right)(\rho(k, 0)-\rho(k, \mu))(1-\Phi)+\frac{\zeta \Phi}{k}
$$

use having been made in the second term of (3.3), recalling (from (F.1)) that $\rho_{k}=0$ when $\mu=1$. From (2.7), taking $\int_{-\infty}^{R} r \phi(r) d r \approx 0$,

$$
\rho(k, \mu)=\frac{\mu \zeta}{1-\Phi+\mu \Phi}
$$

and so

$$
\rho(k, 0)-\rho(k, 1)=\frac{\zeta \Phi}{1-\Phi}
$$

Substituting (A2.3) into (A2.1) and multiplying by $-k^{2}$ to convert this into a tax on borrowing, the result follows on recalling that $D k / K=1-k$.

\section{Appendix 3. Proof of Proposition 3}

Using $D / K=(1-k) / k$ in (3.11), revenue from a corrective proportional tax on deposits is

$$
T^{D} D=-\frac{(1-\mu) \phi R_{k} k(1-k) \Delta}{1+\lambda}-\mu k(1-k) S_{k} K
$$

Part (a) follows on comparing the first term on the right of (A3.1) with the expected cost of the collapse externality $(1-\mu) \Phi \Delta$.

For part (b), it suffices to show that $-k(1-k) S_{k}>S$. To see this, note from (2.11) that

$$
\begin{aligned}
-k(1-k) S_{k} & =(1-k) S-(1-k) R_{k} \Phi \\
& =(1-k) S+R_{k} \Phi-(1-k)^{2} \rho_{k} \Phi \\
& =S+\int_{-\infty}^{R} r \phi d r-(1-k)^{2} \rho_{k} \Phi>S
\end{aligned}
$$

the second equality using the implications of (2.10) that $R_{k}=\rho_{k}(1-k)-\rho$, and the third following from (A1.2). 


\section{Appendix 4. Proof of Proposition 7}

Part (a) is immediate from (5.3), (3.4), and the second order condition. Part (b) follows on adding and subtracting $\delta \Omega$ in (5.3) to find

$$
\Sigma(k, \mu)=(1-\mu) \Omega[\delta-\Delta]-2\left(\frac{1}{k}\right)^{3} E(r-\zeta)\left[\Omega \delta-2 \mu S_{k k}\right]<0 .
$$

and combining (A1.6) and (2.11) to find

$$
S_{k k}=\frac{2 S}{k^{2}}-\frac{2 R_{k}}{k^{2}}+R_{k k} \Phi+\left(R_{k}\right)^{2} \phi>\frac{2 S}{k^{2}} .
$$

\section{Appendix 5. Proof of Proposition 8}

There are two possibilities. The first is that $T=P\left(k_{1}^{*}, a_{2}\right)-P\left(k_{2}^{*}, a_{2}\right)>0$ (in which case, in the absence of any tax, the self-selection constraint on the low ability type would bind). Then (5.7) holds with equality. To see that (5.8) holds, note that since $k_{1}^{*}<k_{2}^{*}$ and $p_{k a}<0$,

$$
\int_{k_{1}^{*}}^{k_{2}^{*}}\left\{P_{k}\left(k, a_{2}\right)-P_{k}\left(k, a_{1}\right)\right\} d k>0 .
$$

Hence

$$
P\left(k_{2}^{*}, a_{2}\right)-P\left(k_{1}^{*}, a_{2}\right)>P\left(k_{2}^{*}, a_{1}\right)-P\left(k_{1}^{*}, a_{1}\right)
$$

or

$$
-T>P\left(k_{2}^{*}, a_{1}\right)-P\left(k_{1}^{*}, a_{1}\right)
$$

which gives (5.8).

The second possibility is that $P\left(k_{1}^{*}, a_{2}\right)-P\left(k_{2}^{*}, a_{2}\right)<0$, and hence $T=0$. In this case, it is immediate that (5.8) holds. And (5.7) holds because $k_{2}^{*}>k_{1}^{*}>\bar{k}_{1}$ (so that $k_{2}^{*}$ is further along the downward-sloping part of $P\left(k, a_{1}\right)$ than is $\left.k_{1}^{*}\right)$. 


\section{References}

Acharya, Viral, 2009, “A Theory of Systemic Risk and Design of Prudential Regulation,” Journal of Financial Stability, Vol. 5, pp. 224-55.

Acharya, Viral, Lasse Pedersen, Thomas Philippon, and Matthew Richardson, 2010, “Measuring Systemic Risk,” (mimeo; New York: New York University).

Adrian, Tobias, and Markus Brunnermeier, 2009, “CoVaR,” Federal Reserve Bank of New York Staff Reports No. 348.

Bank of England, 2009, The Role of Macroprudential Policy, Discussion Paper.

Baker, Dean, and Travis McArthur, 2009, “The Value of the 'Too Big to Fail' Big Bank Subsidy,” Issue Brief (September) (Washington: Center for Economic and Policy Research).

Bianchi, Javier, and Enrique Mendoza, 2010, “Overborrowing, Financial Crises and 'MacroPrudential’ Taxes,” NBER Working Paper 16091 (Cambridge: National Bureau of Economic Research).

Basel Committee on Banking Supervision, 2010, “An Assessment of the Long-Term Impact of Stronger Capital and Liquidity Requirements,” available via the Internet: http://www.bis.org/publ/bcbs173.htm

Bovenberg, Lans, and Ruud de Mooij, 1994, "Environmental Levies and Distortionary Taxation,” American Economic Review, Vol. 94, pp. 1085-89.

Christiansen, Vidar, and Stephen Smith, 2009, "Externality-Correcting Taxes and Regulation,” CESifo Working Paper No. 2793 (Munich: Center for Economic Studies Information).

Demirgüç-Kunt, Asli, and Harry Huizinga, 2010, “Are Banks Too Big to Fail or Too Big to Save? International Evidence from Equity Prices and CDS Spreads,” European Banking Center Discussion Paper No. 2010-15.

Dewatripont, Matthias, and Jean Tirole, 1993, The Prudential Regulation of Banks (Cambridge: MIT Press).

EEAG, 2011, “Taxation and Regulation of the Financial Sector," The EEAG Report on the European Economy, CESifo, Munich, pp. 147-69. 
Gauthier, Céline, Alfred Lehar, and Moez Souissi, 2010, "Macroprudential Regulation and Systemic Capital Requirements,” Bank of Canada Document de Travail 2010-4 (Ontario: Bank of Canada).

Haldane, Andrew, 2009. "Banking on the State,” presented at the 12th Annual Federal Reserve of Chicago International Banking Conference, September 25, 2009. Available via the Internet: www.bankofengland.co.uk/publications/speeches/2009/speech409.pdf.

Hellman, Thomas F., Kevin C. Murdock, and Joseph E. Stiglitz (2000), "Liberalization, Moral Hazard in Banking and Prudential Regulation: are Capital Requirements Enough?” American Economic Review, Vol. 90, pp. 147-65.

HM Revenue \& Customs, 2010, "Bank Levy,” available via the Internet: http://www.hmrc.gov.uk/budget-updates/autumn-tax/tiin1065.htm

Hoggarth, Glenn, and Victoria Saporta, 2001, "Costs of Banking Systems Instability: Some Empirical Evidence,” Financial Stability Review, Bank of England, June, pp. 148-65.

Huang, Rocco, and Lev Ratnovski, 2009, “The Dark Side of Wholesale Funding,” (mimeo; Washington: International Monetary Fund).

International Monetary Fund, 2010a, A Fair and Substantial Contribution by the Financial Sector: Final Report for the G-20, available via the Internet: www.imf.org/external/np/g20/pdf/062710b.pdf

International Monetary Fund, 2010b, Global Financial Stability Report, Meeting New Challenges To Stability and Building a Safer System, April, Chapter 2, Systemic Risk and the Redesign of Financial Regulation. April.

International Monetary Fund, Financial Stability Board and Basel Committee of Bank Supervisors, 2009, "Guidance to Assess the Systemic Importance of Financial Institutions, Markets and Instruments: Initial Considerations," available via the Internet: www.imf.org/external/np/g20/pdf/100109.pdf

Jeanne, Olivier and Anton Korinek, 2010, "Managing Credit Booms and Busts: A Pigouvian Taxation Approach,” (mimeo; Maryland: Johns Hopkins University).

John, Kose, Teresa John and Lemma Senbet, 1991, "Risk-Shifting Incentives of Depository Institutions: A New Perspective on Federal Deposit Insurance Reform,” Journal of Banking and Finance, Vol. 15, pp. 895-915.

Keen, Michael, 2011, "Rethinking the Taxation of the Financial Sector," CESifo Economic Studies, Vol. 57, pp. 1-24. 
Kocherlakota, Narayana, 2010, “Taxing Risk and the Optimal Regulation of Financial Institutions,” Economic Policy paper, Federal Reserve Bank of Minneapolis.

Korinek, Anton, 2009, “Systemic Risk-Taking: Amplification Effects, Externalities, and Regulatory Responses,” (mimeo; Maryland: University of Maryland).

Levine, Ross, 2005, “Finance and Growth: Theory and Evidence,” (mimeo; (University of Minnesota).

Perotti, Enrico, and Javier Suarez, 2009, “Liquidity Insurance for Systemic Crises,” CEPR Policy Insight No. 31, February.

Pizer, William A., 2002, “Combining Price and Quantity Control to Mitigate Global Climate Change,” Journal of Public Economics, Vol. 85, pp. 409-34.

Radulescu, Doina Maria, 2010, “The Effects of a Bonus Tax on Manager Compensation and Welfare,” CESifo Working Paper 3030.

Roberts, Marc J., and Michael Spence (1976). "Effluent Charges Under Uncertainty,” Journal of Public Economics, Vol. 5, pp. 193-208.

Shackelford, Douglas A., Daniel Shaviro, and Joel Slemrod, 2010, “Taxation and the Financial Sector,” National Tax Journal, Vol. 63, pp. 781-806.

Shavell, Steven, 2010, “Corrective Taxation versus Liability,” American Economic Review, Paper and Proceedings, Vol. 101, pp. 273-76.

Shin, Hyun Song, 2010, “Non-Core Liabilities Tax as A Prudential Tool,” Policy Memo, available via the Internet:

http://www.princeton.edu/ hsshin/www/NonCoreLiabilitiesTax.pdf.

Shull, Bernard, 2010, “Too Big To Fail in a Financial Crisis,” Working Paper No. 601, (New York: Hunter College, City University of New York).

Sinn, Hans-Werner, 2003, "Risk-Taking, Limited Liability, and the Competition of Bank Regulators,” Finanzarchiv, Vol. 59, pp. 305-29.

Sinn, Hans-Werner (2010), Casino Capitalism (New York: Oxford University Press).

Wagner, Wolf, 2010. "In the Quest of Systemic Externalities: a Review of the Literature,” CESifo Economic Studies, Vol. 56, pp. 96-111.

Weder di Mauro, Beatrice, 2010, “Taxing Systemic Risk: Proposal for a Systemic Risk Charge and a Systemic Risk Fund,” (mimeo; Postfach: University of Mainz). 
Weitzman, Martin, 1974, “Prices vs. Quantities,” Review of Economic Studies, Vol. 41, pp. 477-91.

Weitzman, Martin, 1978, "Reply to 'Prices vs. Quantities: A Critical Note on the Use of Approximations,” Review of Economic Studies, Vol. 46, pp. 209-10. 